\title{
Glaucoma in siblings with Morquio syndrome
}

\author{
M Cahane, G Treister, F A Abraham, S Melamed
}

\begin{abstract}
Two cases of association between the Morquio Syndrome and glaucoma in one family are described. Possible role of Mucopolysaccharides acting in the anterior chamber angle is discussed.
\end{abstract}

Morquio syndrome (mucopolysaccharidosis type 4) was first described in $1929 .^{1}$ It is an autosomal recessive error of metabolism in which keratan sulphate is usually excreted in the urine. ${ }^{2-5}$ Deficient activity of the enzymes Nacetygalactosamine 6-sulphatase (Morquio type A), or acid-b-galactosidase (Morquio type B) has been reported in this disease. ${ }^{5-8}$

The syndrome is characterised by severe skeletal changes which include hypoplasia of the odontoid process, short neck, pectus carinatum, kyphoscoliosis, and dwarfism. There are also laxity of joints and characteristic roentgenographic findings. ${ }^{2-4}$ Other manifestations include aortic regurgitation, thinness of tooth enamel, and neurosensory deafness. ${ }^{2}$ The syndrome is distinguished from other mucopolysacharidoses by the absence of mental retardation. ${ }^{2-4910}$ Clinical findings develop in early childhood and are not apparent at birth. ${ }^{29}$

The most striking ocular finding is corneal stromal clouding, which is present in nearly all cases but may not be evident until adolescence. ${ }^{2369}$ Retinal involvement, slight scotopic impairment, and blurred discs have also been reported. ${ }^{211}$

Glaucoma is not considered to be part of the Morquio syndrome. We have found only one report of two brothers with bilateral buphthalmos, ${ }^{12}$ and in another case extensive anomalies of mesodermal iris tissue were observed in the anterior chamber angle. ${ }^{9}$

In this report we describe an unusual case of two siblings (a brother and a sister), aged 35 and 36 years respectively, with Morquio syndrome and glaucoma.

\section{Case reports}

Maurice and Gabriela Goldschleger Eye Institute (Sackler School of Medicine), Tel-Aviv University, Chaim-Sheba Medical Center, TelHashomer, 52621, Israel M Cahane

G Treister

F A Abraham

$S$ Melamed

Correspondence to: $M$ Cahane, MD, Maurice and Gabriela Goldschleger, Eye Institute, Chaim-Sheb Medical Center, TelHashomer, 52621, Israel. Accepted for publication 23 January 1990

\section{CASE 1}

This was a 35-year-old man who was diagnosed many years ago as having Morquio syndrome. His 36-year-old sister has the same disease. Another brother died at the age of 22 and had Morquio syndrome. Both parents and another brother are healthy. Since childhood the patient has had corneal clouding in both eyes. Three years ago a high intraocular pressure (IOP) of 30 $\mathrm{mmHg}$ was measured in both eyes. Treatment with topical drops of $2 \%$ pilocarpine four times a day and later $1 \%$ epinephrine twice daily was given in both eyes. In the last year the IOP was not controlled despite the addition of $0.5 \%$ timolol maleate twice daily, and he was referred to our clinic for further evaluation.

On examination the patient's height was found to be $82 \mathrm{~cm}$. He had kyphoscoliosis, a short neck, pectus carinatum, and laxity of joints.

The visual acuity was $20 / 100$ in both eyes. Both corneas had hypoaesthesia and stromal clouding, more dense centrally. The stromal clouding contained a large number of small dustlike opacities. The IOP (under full topical treatment) was $31 \mathrm{mmHg}$ in both eyes as measured both by Goldmann applanation and Schiøtz tonometry. The anterior chamber was deep and the iridocorneal angle was open, but the detailed structures could only be poorly visualised due to corneal haziness. The lens appeared clear, and the fundus could not be examined in detail. The axial length was $26.5 \mathrm{~mm}$ in the right eye and $27.0 \mathrm{~mm}$ in the left. Visual field testing showed generalised constriction in both eyes.

The electroretinogram (ERG), evoked by full field light flash stimulation, showed responses of normal amplitude and implicit times of both photopic and scotopic retinal mechamisms. The visual evoked potentials (VEP) showed normal stimulus propagation through the optic pathway. Colour vision was normal.

\section{CASE 2}

This patient was a 36-year-old female, the sister of case 1. She also has Morquio syndrome, with severe dwarfism. She is known to have had corneal clouding in both eyes for many years.

A raised IOP in both eyes was found five years ago, and since then she has been treated with $1 \%$ epinephrine and $0.5 \%$ timolol meleate twice daily. She was referred to us for further evaluation of her ocular status.

On examination her height was found to be 75 $\mathrm{cm}$. She had kyphoscoliosis, a short neck, pectus carinatum, and a cardiac murmur due to aortic regurgitation.

The visual acuity was $20 / 100$ in both eyes. The IOP was $31 \mathrm{mmHg}$ without treatment. Both corneas had hypoaesthesia and diffuse stromal clouding, containing numerous small dust-like opacities. The anterior chamber was deep, and gonioscopy revealed an open angle, but the details could not be examined owing to corneal opacity. The lens was clear in both eyes, and fundus examination was impeded by a hazy view. The axial length was $22.0 \mathrm{~mm}$ in the right eye and $21.1 \mathrm{~mm}$ in the left. No specific visual field defects other than generalised constriction of field were found.

The ERG recordings showed normal photopic and scotopic responses, and the VEP revealed normal conduction in the optic pathway. Colour vision was normal. 


\section{Discussion}

In the mucopolysaccharidoses there is a deficiency in enzymes degrading mucopolysaccharides. Consequently mucopolysaccharides accumulate in various organs, including the corneal stroma. It is of interest that glaucoma has not been associated with these diseases, though one would expect to see more cases of glaucoma due to mucopolysaccharide accumulation in the trabecular meshwork. It is believed that proteoglycans in the trabecular meshwork contribute to the resistance of the aqueous outflow. ${ }^{13}$ Knepper et $a l^{14}$ have used selective glycose aminoglycans (GAGS) enzyme degradative procedures to identify GAGS in the trabecular meshwork of eyes with primary open-angle glaucoma. They found that hyaluronic acid was decreased, while chondroitin sulphate and GAG-enzyme resistant material were raised. Therefore it is suggested that accumulation of these materials is important in the pathogenesis of glaucoma.

Lack of glaucoma in most cases of mucopolysaccharidosis may be explained by the short life of these patients. In Morquio syndrome, however, the life span is longer, so that there is more time for the accummulation of mucopolysaccharides in the trabecular meshwork, resulting in glaucoma.

In this report we present two siblings with Morquio syndrome, with corneal stromal clouding and glaucoma. In contrast to patients with Morquio syndrome previously described in the ophthalmic literature, who are usually children or adolescents, our patients are older. It is possible that alterations of the metabolism of mucopolysaccharides affect the trabecular mesh- work slowly, and so glaucoma appears at an older age.

We suggest therefore that patients with Morquio syndrome should be examined with special attention to detect signs of glaucoma, and topical treatment should be initiated if a raised intraocular pressure is found.

1 Morquio L. Sur une forme de dystrophie osseuse familiale. Bull Soc Pediatre (Paris) 1929; 27: 145-52.

Dangel ME, Tsou BHP. Retinal involvement in Morquio's syndrome (MPS 4). Ann Ophthalmol 1985; 17: 349-54.

3 François J. Ocular manifestations of the mucopolysaccharidoses. Ophthalmologica 1974; 169: 345-61.

4 Kenyon KR, Quigley HA, Hussels JE, Wyllie RG. The systemic mucopolysaccharidoses. Ultrastructural and histosystemic mucopolysaccharidoses. Ultrastructural and histo-
chemical studies of conjunctiva and skin. Am $\mathcal{F}$ Ophthalmol

5 Summers C G, Purple RL, Krivit W, et al. Occular changes in the mucopolysaccharidoses after bone marrow transplantation. Ophthalmology 1989; 96: 977-85.

6 Nelson J, Broadhead D, Mossman J. Clinical findings in 12 patients with MPS 4A (Morquio's disease). Further evidence of heterogeneity. Part 1: Clinical and biochemical findings. Clin Genet 1988; 33: 111-20.

7 Giugliani R, Jackson M, Skinner SJ, et al. Progressive mental regression in siblings with Morquio disease type B. Clin regression in siblings

8 Singh J, Diferrante NM, Niebes P, Tavella D. Nacetylgalactosamine-6-sulfate sulfatase in man: absence of the enzyme in Morquio disease. $\mathcal{F}$ Clin Invest 1976; 57 : 103640.

9 Von Noorden GK, Zellweger H, Ponseti IV. Ocular findings in Morquio-Ulrich disease. Arch Ophthalmol 1960; 64: 585-

10 Gills JP, Hobson R, Hanley WB, McKusick VA. Electroretinography and fundus oculi findings in Hurler disease and allied mucopolysaccharidoses. Arch Ophthalmol 1965; 74: 596-603.

11 Abraham FA, Yatziv S, Russell A, Auerbach E. A family with two siblings affected by Morquio syndrome (MPS 4). Arch two siblings affected by Morq

12 Davis DB, Currier FP. Morquio's disease: report of two cases. FAMA 1934; 102: 2173-6.

13 François J. The importance of mucopolysaccharides in intraocular pressure regulation. Invest Ophthalmol Vis Sci 1975; 14: $173-6$.

14 Knepper PA, Hvizd MG, Gossens W, Higbee RG, Gum GG, Palmsbery PF. GAG profile of TM in primary open angle glaucoma. Invest Ophthalmol Vis Sci 1989; 30 (suppl): 224. 